\title{
Research on the Standardized Development Path of Physical Education Teachers' Professional Ethics
}

\author{
ZHOU Bo \\ Department of Police Skills and Tactics \\ Nanjing Forest Police College \\ Nanjing 210023, China \\ zhoubo@nfpc.edu.cn
}

\author{
ZHANG Fan* \\ Department of Police Skills and Tactics \\ Nanjing Forest Police College \\ Nanjing 210023, China \\ zhangfan@nfpc.edu.cn
}

\begin{abstract}
The normalization should be adopted as the route, basis, method and standard for the development of physical education teachers' professional ethics. The documentary analysis and other methods are adopted to study the professional ethics of physical education teachers. Through the innovative practice of the school's posts, working systems as well as the education, teaching and educational research, the combination of the contents and practices of physical education teachers' schoolbased education, academic education, further education and the specialized moral education can effectively promote the professional ethics of physical education teachers to keep pace with the times and the teaching reform in university, and improve the development of education and teaching innovation. The main conclusion is that the professional ethics of physical education teachers are the fundamental spiritual power of this group's conscious development, scientific development and sustainable development.
\end{abstract}

Keywords-physical education; PE teachers; professional ethics; teachers morality; employment standards

\section{INTRODUCTION}

Both as the workers within the education and teaching system, and the most active occupational group in the society, for physical education teachers, their professional ethics as well as the power, room and direction of their sustainable development greatly affect the education, teaching and social morality. The use of the existing system and mechanism for teacher's education and training, school's educational resources, school-based training methods as well as the development schemes and experience for teacher's ethics can more effectively promote the physical education teachers to develop their professional ethics on the post and in subject teaching.

\section{NORMALIZATION OF PHYSICAL EdUCATION TEACHERS' PROFESSIONAL ETHICS}

As one of the professional performances, teachers' professional ethics are their adherence to professional ethics and innovation in the specific work and the spare time.

\section{A. Normalization of Post}

Physical education teachers show their understanding of professional ethics according to the requirements by their work of education and teaching, through their own practice and personal innovation. From the practical situation of work by teachers in universities and colleges, there are two types of posts. The first one is classroom teaching. In the classroom teaching, Teachers not only carry out a variety of educations about professional knowledge, technical skills, ideology and morality through their own dedication, profession and devotion, but also set the goals for learning and improvement for students through the teachers' own exemplary role, such as the tender care for students under the weather during the teaching. The second one is educational research, including the preparation for lessons, teaching and research activities, educational research activities and other activities about teaching; these are both personal activities and team activities like the teaching and research groups, subject departments and research groups. It is the basis for them to teach lessons and do academic researches as well as carry out the teaching innovation. For example, teachers can guide classroom teaching with their own research results.

\section{B. Normalization of Rules}

For physical education teachers, there are two rules that can reflect professional ethics--educational laws and regulations as well as school discipline. It is the basic professional integrity of physical education teachers to abide by the laws, regulations and policies for education and teaching in the towns, provinces and cities, and the relevant school disciplines [1]. Both their individual behaviors and education and teaching activities need to be carried out within the scope of laws and regulations, so they should set the example of observing law and discipline. The various rules of sports competition is the special professional ethics for physical education teachers. Only under specific rules, can they really test their own teaching result and fully understand their own professional skills. Teachers' respect and loyalty for the rules can fully reflect their respect for the major, so that they would carry out their work rigorously and earnestly with awe.

\section{DEVELOPMENT PATH OF NORMALIZATION FOR} Physical EduCATION TEACHERS' ProfESSIONAL ETHICS

The development of the normalization for physical education teachers' professional ethics requires both specialized and professional moral education, and the 
training, experience and inspiration in their work and practice.

\section{A. School-based Education}

School-based education is the process when the colleges and universities actively develop the teachers' moral education resources in the school and the department of physical education, allowing the physical education teachers to actively study and use the resources such as the campus culture as well as moral model of teachers and students in their own work and practice, for self-education, self-practice and self-promotion. There are two kinds of effective operating mode for schoolbased education, namely the design and application of schoolbased teaching materials. Colleges and universities use the existing teacher resources and the resources of writing talents, to write the teaching material of school culture with the characteristics of the school. Adopting appropriate forms for education is one of the best ways for the schools to carry out professional ethics education [2]. According to the current reality, the teaching materials are mainly given out to teachers for free or adopted as books in school libraries, so that teachers can feel free to read as needed and the school-based work with stories of teachers' and students' good deeds can be enriched and used. At the same time, people with positive energy and optimism will be found and their spirit will be carried forward after the publicity by the specially-written teaching materials or works. These books can guide students to make a comparison between themselves and the people in the book and help them find the gaps and problems, which can play a practical role in ideological and moral education. Besides, teachers will be touched by the ideas and improve their souls as well as strengthen their political beliefs.

\section{B. Further Education}

From the management, organization and form of assessment for further education, further education is the important way for the official to use the control of institution and mechanism for forcing teachers to carry out lifelong learning and improve the teacher's ethics and personal professional qualities [4]. Combining with the present practice, the teachers' professional ethics education is one of the contents that must be carried out with the times, and there are two ways to conduct. The first one is the education with the specialized teaching materials for ethics. During each year or each period of further education, the education authorities would organize the design and use of the up-to-date teaching materials for ethics, and carry out specialized educational activities on teachers of each department, which can be specialized lectures or the free discussion between teachers. It is intended to mobilize the enthusiasm of teachers to actively participate in further education and to adopt more cases and opinions out of class as well as to carry out practical educational activities in the case of relying on relevant teaching materials. The second is the education with the teaching materials for education and teaching techniques. As an educational model for professional training in terms of teachers' professional education and teaching techniques, further education is a way of lifelong education based on the realities of profession and subject. This kind of teaching material summarizes the teachers' professional process, professional effect, professional method, professional ideal and professional practice. It is not only the reflection of the teachers' professional ethics but also one of the positive achievements of professional ethics.

\section{Construction of Teachers' Ethics}

The construction of teachers' ethics in colleges and universities is not only the necessary content of the construction of teaching staff, but also the important carrier for the continuous development of the teaching staff's cohesion, unity and power. This is the best way to combine administrative management with self education. Besides, the institution, content, system and mode of the moral construction is distinctively administrative; the effect of moral construction, the moral practice and the development of morality is directly related to the individual's efforts and practice. There are two kinds of mode for development. The first one is the organization-based construction of teachers' ethics. This organization takes the schools or departments as the main units. The schools often develop macro programs, medium-term and long-term plans, annual work plans and even the work plans of each semester for professional ethics [3]. The specific implementation is generally on the basis of the departments where the teachers work. Through the development of annual or semester-based implementation details, the moral education is carried out in accordance with the reality. The second is the individual-based construction of teachers' ethics. This is the form when the teachers carry out independent learning arranged by the schools or the departments. The teachers study and make reading notes according to school-based teaching materials about teachers' ethics. Besides, they actively adopt network, learning materials from school libraries and other channels for learning activities according to the general requirements by the schools. For example, with the column of teachers' ethics on the schools' websites, the websites of teacher resources, the Ministry of Education's website and other resources, they can constantly improve their ideological and moral level through reading and thinking about more advanced persons and deeds.

\section{Academic Education}

For teachers in universities and colleges, academic education is one of the important ways for their professional development and innovation in education and teaching techniques. From the perspective of the benefits from reading books and the all-round improvement of the individual's quality, the academic education systematically and constantly strengthen and promote the professional ethics education [5]. There are two kinds of academic educations. The first one is the academic education for the physical education teachers' physical education major, mainly referring to the forms of education of master's degree and doctor's degree. Through this education, their individual pursuit is improved, so they will improve their professional ethics more profoundly and professionally in the systematic learning. In this process, the physical education teachers will make more in-depth thinking, especially reflective thinking based on their own education and teaching, so that their construction of teachers' ethics can be improved from the professional skills and competitive rules, to combine the teachers' ethics, profession and major with the strong sense of responsibility, professional dedication and professional sensitivity. The second is the academic education 
of non-physical education major for physical education teachers. In order to broaden their professional foundation and horizons, physical education teachers can carry out crossdisciplinary education and learning, so that they can understand their own career, teaching, students, professional development and the students' further employment as well as career development with more comprehensive and advanced views[6]. Especially, they can take into consideration when carrying out education and teaching as well as related research and innovation activities.

\section{SYSTEMS OF NORMALIZATION FOR PHYSICAL EDUCATION TEACHERS' PROFESSIONAL ETHICS}

As a systematic long-term soul project, the normalization for physical education teachers' professional ethics, not only needs schools to make flexible changes with the actual situation, but also needs the faculties and teachers to personally carry out individual learning activities. Besides, the education authorities of the country, provinces and counties should establish legal environment and improve the system and mechanism, which protects the scientific development for the physical education teachers' professional ethics.

\section{A. Use of relevant laws}

Adopting laws to regulate and guide the construction of physical education teachers' professional ethics and daily education work is the basis to protect the team of physical education teachers and its scientific development of professional ethics. According to China's current legal system, it mainly refers to the use of three types of laws and regulations. The first category is education law, mainly including the Education Law, Teacher's Law, Higher Education Law, Vocational Education Law and other basic laws. These lays have detailed provisions and guidance about the construction, rewards and punishment, contents and other aspects of the teachers' professional ethics. The second category is the education regulations, mainly referring to the detailed rules regulations with the role of guidance for the enforcement under the above-mentioned basic education laws, such as Regulations on Academic Degrees, Regulations on the Qualifications of Teachers, Rules and Regulations of School Physical Education and The Rules of Administrative Penalties for the Implementation. The application of these regulations or regulations can promote the construction of physical education teachers' professional ethics and daily education activities with strong operation. The third category is the the administrative provisions on the professional ethics of teachers, which is mainly reflected in the provisions of the special moral cultivation. These provisions not only refer to special stipulation on the teachers' ethics, but also include the supplemental provisions based on the various events of the new era as well as the flexible and organic achievements according to the relevant education laws and regulations. Among them, for the provisions of local provinces and cities as well as schools, the provisions on the construction of teachers' ethics turn it into concrete management activities and construction activities which can be conducted. In addition, the rules of various events and competitions are also the scientific, rigorous and operational specific provision on the normalization of the physical education teachers' ethics. The laws and regulations of different levels form various strict provision on the physical education teachers' professional ethics and also form a very comprehensive system for guidance.

\section{B. Supplement of School System}

Schools or departments develop and implement a variety of system for teachers' ethics according to the actual situation, which is the most effective way and environment for the physical education teachers' professional ethics education [7]. There are three main systems at present. The first is the management system for professional ethics, mainly referring to all the systems that stipulate what the physical education teachers should or should not do in accordance with the actual situation of the school, in terms of the post, major, the scientific research, the relationship between teachers and students and so on, driving the physical education teachers to actively carry out learning and continuous improvements with the authoritative coerciveness [8]. The second is the reward and punishment system. This is the guiding system that adopt the guidance by rewards and the warning by punishment, so that the physical education teachers can choose their own way of act based on their own situations and make a variety of forward-looking thinking for various results as well as forecast based on this. For the problems or defects that are likely to be exposed to, they should correct and perfect themselves through special studying from the personal professional ethics. The third is the system for learning and assessment, including the vocational study, ptual evaluation, managers' evaluation and other multi-level, multiperspective evaluation are adopted, to pursue the comprehensive, scientific and practical evaluation on the teachers' professional ethics, in order to truly reflect the dynamic development of teachers and the professional ethics of the overall team as well as individuals.

\section{CONCLUSION}

The normalization of physical education teachers' professional ethics is the comprehensive effect of the education law and its detailed rules and regulations, China's education institutions and systems, the schools' specific systems and the implementation plans, with the team's efforts, individuals' efforts and growth. Therefore, the way of normalization is to observe law and discipline as well as to have rules to follow, which includes not only the guidance by the typical models but also the systematic, normalized and scientific professional theories that is continuously enriched and summarized, creating a platform with flexibility, affection and warmth for the construction and development of the physical education teachers; professional ethics. 


\section{ACKNOWLEDGMENT}

This work was supported in part by the Project of the Fundamental Research Funds for the Central Universities under Grant LGZD201709, in part by the Project of China Postdoctoral Science Foundation under Grant 2017M611849, in part by Jiangsu Qing LAN Project under Grant 2017, and in part by Nanjing Forest police College Teaching Reform Project under Grant ZD17001 \& YB17001.

\section{REFERENCES}

[1] XIA Duan-yang. Needs and ways to enhance the quality of teachers' Professional Academy. JOURNAL OF WUHAN INSTITUTE OF PHYSICAL EDUCATION, vol. 42, pp. 86-89, January 2008. (In Chinese)

[2] Cui Lili, Zhang Zhiyong, Li Jing. Analysis of Physical Education Teachers' Professional Identity and Social Status Perception. Journal of Beijing Sport University, vol. 40, pp. 82-88, July 2017. (In Chinese)
[3] Gou xiao-feng. Thoughts on the construction of physical education teaching staff in Colleges and Universities. Education and Vocation, vol. 21, pp. 78-79, December 2016. (In Chinese)

[4] Di Jian-yong, Yang Yan-mei. Construction of values of College Physical Education Teachers under the new normal. Education and Vocation, vol.21, pp. 84-86, November 2016. (In Chinese)

[5] YU Xue-lian, PENG Xue-ling. Research on the Professionalism Model Construction of PE Teachers from the Respective of Public Health Service. Journal of Guangzhou Sport University, vol. 34, pp. 119-121, May 2014. ( In Chinese)

[6] ZHU Xiu-qing, ZHANG Huan. Evaluation System of College PE Teachers' Professional Quality. Journal of Chengdu Sport University, vol. 40, pp. 85-90, June 2014. (In Chinese)

[7] CHENG Chuan-yin. Re-understanding of Educational Knowledge Basis of P.E.Teachers. Journal of Wuhan Institute of Physical Education, vol. 47, pp. 73-77, April 2013. (In Chinese)

[8] ZHANG Shao-wei. Why to Teach: P. E. Teachers Professional Ethics Building Foundation. Journal of Beijing Sport University, vol. 35, pp. 100-104, October 2012. (In Chinese) 